\title{
How Cats Can Be Sensitized to Foreign Protein
}

\begin{tabular}{|l|l|}
\hline A. & Akcasu \\
\hline
\end{tabular}

University of Istanbul, Faculty of Medicine, Istanbul

Author's address: Dr. A. Akcasu, Deot of Pharmacology, Faculty of Medicine. Univ. of Istanbul, Istanbul (Turkey)

It has been suggested that the antigenic specificity of foreign proteins is changed in the cat by an unidentified enzyme system. Since capacity of this system appears to be limited, excess antigen may enable the cat to produce specific antibodies so that anaphy-laxis may occur.

Cats were anaesthetised with intraperitoneal pentobarbital $(25 \mathrm{mg} / \mathrm{kg})$ and then quantities of horse serum up to $100 \mathrm{ml}$ were infused intravenously over the next $4 \mathrm{~h}$. After a wait of at least 20 days, the animals were challenged intravenously with $0.5 \mathrm{ml}$ of the original antigen. The criteria taken for anaphylactic shock were (a) a prolonged fall in blood pressure, (b) an increase in capillary permeability, (c) an increase in haematocrit value, and (d) a good precipitin reaction of the cat plasma with the antigen.

The fall in blood pressure in most of ten cats challenged persisted, after an initial transient fall lasting $3 \mathrm{~min}$., for the next $20 \mathrm{~min}$ and then half of the animals died. Those which survived were re-injected with the antigen without result. Permeability changes in the skin capillaries were noted by injecting the antigen intradermally after intravenous blue dye. The haematocrit values of the blood samples were significantly raised.

In all experiments, suitable control unsensitised cats were similarly tested but with negative results. The precipitin tests gave rather inconsistent results. It appears that cats can be sensitised to foreign protein if sufficient antigen is administered at the time of sensitisation. 